\title{
LA INEXISTENCIA DE FINALIDAD MEDIOAMBIENTAL EN EL IMPUESTO SOBRE EL VALOR DE LA PRODUCCIÓN DE ENERGÍA ELÉCTRICA (IVPEE) Y SUS CONSECUENCIAS JURÍDICAS ${ }^{1}$
}

\section{THE ABSENCE OF AN ENVIRONMENTAL PURPOSE IN THE VALUE ADDED TAX ON ELECTRICITY PRODUCTION (V.I.P.E.) AND ITS LEGAL CONSEQUENCES}

\author{
ALEJANDRO D. LEIVA LóPEZ \\ Profesor Ayudante Doctor \\ Área de Derecho Administrativo \\ Universidad Rey Juan Carlos \\ alejandro.leiva@uric.es
}

Fecha de recepción: 14 de mayo de 2020 / Fecha de aceptación: 6 de julio de 2020

RESUMEN: El presente trabajo tiene por objeto analizar la legitimidad del Impuesto sobre el Valor de la Producción de Energía Eléctrica (IVPEE), desde la perspectiva de su constitucionalidad y de su adecuación a la normativa europea. En particular, se analiza la pretendida finalidad medioambiental que la Ley 15/2012 atribuye al IVPEE y las importantes implicaciones jurídicas que ello comporta. Sobre este punto, en el momento en que se escriben estas líneas, se espera el inminente pronunciamiento del Tribunal de Justicia de la Unión Europea, acerca de una cuestión prejudicial planteada por el Tribunal Superior de Justicia de Valencia en relación con la falta de adecuación del IVPEE al Derecho de la Unión. Este esperado fallo va a tener destacadas implicaciones jurídicas, ya que si el tribunal concluye que no se desprende finalidad medioambiental alguna de los elementos del IVPEE, los generadores de electricidad que hayan impugnado sus autoliquidaciones hasta obtener una

\footnotetext{
${ }^{1}$ Este trabajo ha sido realizado en el marco del Proyecto de Investigación "Sostenibilidad energética y entes locales: incidencia del nuevo paquete energético de la Unión Europea" (DER2017-86637-C3-2-P), Ministerio de Economía y Competitividad, Programa Estatal de Fomento de la Investigación Científica y Técnica de Excelencia, Subprograma Estatal de Generación del Conocimiento, Convocatoria 2017.
} 
sentencia firme, podrán iniciar acciones de responsabilidad patrimonial por los daños causados por una norma contraria al Derecho de la Unión; recuperando así los ingresos indebidos efectuados a la Agencia Estatal de Administración Tributaria.

RESUM: El present treball té per objecte analitzar la legitimitat de l'impost sobre el Valor de la Producció d'energia elèctrica (IVPEE), des de la perspectiva de la seva constitucionalitat i de la seva adequació a la normativa europea. En particular, s'analitza la pretesa finalitat mediambiental que la Llei 15/2012 atribueix a l'IVPEE i les importants implicacions jurídiques que això comporta. Sobre aquest punt, en el moment en què s'escriuen aquestes línies, s'espera l'imminent pronunciament de Tribunal de Justícia de la Unió Europea, sobre una qüestió prejudicial plantejada pel Tribunal Superior de Justícia de València en relació amb la manca d'adequació de l'IVPEE a el Dret de la Unió. Aquest esperat fallada va tenir destacades implicacions jurídiques, ja que si el tribunal conclou que no es desprèn finalitat mediambiental alguna dels elements de l'IVPEE, els generadors d'electricitat que hagin impugnat els seus autoliquidacions fins a obtenir una sentència ferma, podran iniciar accions de responsabilitat patrimonial pels danys causats per una norma contrària a el Dret de la Unió; recuperant així els ingresos indeguts efectuats a l'Agència Estatal d'Administració Tributària.

ABSTRACT: In this paper, we examine the legitimacy of the Tax on the Value of Electricity Generation, from the perspective of its constitutionality and its compatibility with the European Union Law. In particular, we examine the environmental goal that the Law 15/2012 attributes to the Tax on the Value of Electricity Generation, and its important legal implications. On this point, at the present time, we are waiting for the pronouncement of the Court of Justice of the European Union, in relation to a preliminary ruling raised by the High Court of Justice of Valencia, because it has appreciated the mismatch between this state tax and the European Union Law. This expected pronouncement is going to have important legal implications, because if the Court of Justice of the European Union concludes that there is no environmental goals in the elements of the tax, the electricity generators may initiate state liability proceedings, on the occasion 
of damages caused by a state law in conflict with the European Union Law. In this way, they could recover the undue income paid to the Spanish Tax Agency.

PALABRAS CLAVE: Sector eléctrico - Impuesto sobre el Valor de la Producción de la Energía Eléctrica (IVPEE) - Doble imposición- Derecho de la Unión Europea - Fines medioambientales.

PARAULES CLAU: Sector elèctric - L'impost sobre el Valor de la Producció de l'energia elèctrica" (IVPEE) - Doble imposició- Dret de la Unió Europea - Fins medioambientals.

KEYWORDS: Electricity sector - The Tax on the Value of Electricity Generation (IVPEE) - Double taxation - European Union Law - Environmental goals.

SUMARIO: I. INTRODUCCIÓN. II. LA GENERACIÓN DE ELECTRICIDAD EN EL ACTUAL ESCENARIO TECNOLÓGICO Y REGULATORIO1. Hoja de ruta para la transición energética. 2. El importante papel de las energías renovables. III. LA CREACIÓN DEL IVPEE 1. Marco normativo: la Ley 15/2012. 2. Concepto y naturaleza jurídica. 3. Hecho imponible. La posible existencia de doble imposición. 4. Circunstancias que motivaron su adopción: la situación deficitaria del sistema eléctrico español. 5. La suspensión del IVPEE. Causas y efectos. IV. LA POSIBLE EXISTENCIA DE DOBLE IMPOSICIÓN ENTRE EL IVPEE Y EL IAE. 1. Posiciones a favor de la existencia de doble imposición 2. Pronunciamientos del Tribunal Constitucional. V. LA COMPATIBILIDAD ENTRE EL IVPEE Y EL DERECHO DE LA UNIÓN EUROPEA. 1. EI IVPEE como impuesto indirecto. 2. Normativa europea afectada. 3. Acerca de la pretendida finalidad medioambiental del IVPEE. 4. El planteamiento de cuestión prejudicial por parte del Tribunal Superior de Justicia de Valencia. VI. CONCLUSIONES. VII. BIBLIOGRAFÍA

\section{INTRODUCCIÓN}

La llegada del Impuesto sobre el Valor de la Producción de Energía Eléctrica (en adelante, IVPEE) se remonta al año 2012, y desde entonces se han venido sucediendo numerosos pronunciamientos acerca de su posible falta de adecuación a la Constitución Española y al Derecho de la Unión Europea. Esta pretendida falta de legitimidad del IVPEE, como vemos en adelante, sigue siendo objeto de un intenso debate en la fecha en que se escriben estas líneas. Cabe adelantar que el hecho imponible que grava el IVPEE es distinto al previsto en el Impuesto Especial de la Electricidad, donde se grava el suministro de energía eléctrica para consumo. 
Se trata de un impuesto que grava la energía eléctrica generada desde todas las modalidades de centrales de producción. En concreto, aplica un tipo del $7 \%$ a todo ingreso que provenga de la incorporación y venta de energía eléctrica. Asimismo, se subraya el carácter medioambiental de este impuesto, en tanto está gravando una actividad que provoca un desarrollo de infraestructuras de red que tienen gran impacto medioambiental. Las instalaciones generadoras de electricidad ocasionan grandes refuerzos en las redes de electricidad necesarias para evacuar la electricidad vertida, lo que requiere de elevadas partidas de inversión destinadas a tal concepto, en aras de mantener un adecuado nivel de garantía de suministro. Sin embargo, esta pretendida finalidad se ha puesto en entredicho y, con ello, la legitimidad del IVPEE; ya que algunas voces atribuyen a este impuesto un carácter estrictamente recaudatorio.

En este orden de cosas, el presente trabajo persigue analizar la legitimidad del IVPEE, desde la perspectiva de su adecuación a la Constitución Española y al Derecho de la Unión. Destacadamente, el Tribunal de Justicia de la Unión Europea (en adelante, TJUE) está enjuiciando una posible falta de compatibilidad entre el IVPEE y el Derecho de la Unión Europea, lo que ha provocado una reacción inmediata de los contribuyentes. Así, los generadores están emprendiendo acciones legales encaminadas a recuperar, llegado el momento, las cargas tributarias soportadas. En concreto, los contribuyentes están impugnando las autoliquidaciones del impuesto mediante peticiones de devolución de ingresos indebidos efectuados ante la Agencia Estatal de Administración Tributaria (AEAT), lo que les permitiría acudir en última instancia a los tribunales de justicia ${ }^{2}$. De manera que llegados a sede judicial y obtenida una sentencia firme desestimatoria, tal y como exige el artículo 32.5 Ley 40/2015, de 1 de octubre, de Régimen Jurídico del Sector Público (en adelante, LRJSP) ${ }^{3}$, el contribuyente podría emprender una acción de responsabilidad patrimonial por daños causados por una norma contraria al Derecho de la Unión Europea, lo que

\footnotetext{
2 Pablo Renieblas Dorado, "Impuesto sobre el Valor de la Producción de la Energía Eléctrica: plazo de prescripción del derecho a solicitar la devolución de ingresos indebidos en el Impuesto sobre el Valor de la Producción de Energía Eléctrica. Pagos fraccionados", en Carta Tributaria. Revista de Opinión, núm. 28, 2017, pp. 1-10.

${ }^{3}$ BOE núm. 236, de 02 de octubre de 2015.
} 
tendría lugar en el momento en que el TJUE resolviese, en su caso, a favor de la incompatibilidad entre el IVPEE y el derecho europeo.

Además, este tan esperado fallo del TJUE podría condicionar el devenir de la normativa eléctrica con carácter general, ya que el IVPEE se devuelve a los generadores renovables a través del sistema retributivo primado vigente previsto para este tipo de generadores. Por tanto, aquellos generadores renovables que no recurran en los términos señalados, no recuperarían las cantidades satisfechas en concepto de IVPEE y además verían reducida su retribución primada a futuro. Todas estas cuestiones serán objeto de análisis en el presente trabajo.

\section{LA GENERACIÓN DE ELECTRICIDAD EN EL ACTUAL ESCENARIO TECNOLÓGICO Y REGULATORIO}

\section{Hoja de ruta para la transición energética}

Como es sabido, la energía eléctrica es un producto de primera necesidad del que no cabe prescindir en un escenario de crecimiento económico y social. Así, la electricidad aparece como un elemento básico cuyo suministro debe quedar garantizado en todo momento, ya que cualquier fallo, por pequeño que sea, va a provocar grandes problemas para los hogares (en relación con la calefacción, el agua caliente sanitaria, los electrodomésticos básicos...) y para la industria (especialmente, la electrointensiva) ${ }^{4}$.

El sector eléctrico español presenta una industria basada fundamentalmente en la utilización de recursos fósiles, lo que no contribuye a alcanzar los niveles adecuados de sostenibilidad ambiental que se demandan a nivel europeo e internacional ${ }^{5}$. En este contexto, a nivel europeo, los objetivos de

\footnotetext{
${ }^{4}$ Joaquín María Nebreda Pérez, "El régimen especial de producción eléctrica", en Santiago Muñoz Machado (dir.), Derecho de la regulación económica, Vol. 3, Tomo 1, lustel. Madrid, 2009, pp. 381-385.

${ }^{5}$ Luciano José Parejo Alfonso, "Cambio regulatorio, sector eléctrico y estado de necesidad", en Juan Castro Gil-Amigo (coord.), Riesgo regulatorio en las energías renovables, vol. 1, Thomson Reuters-Aranzadi. Navarra, 2015, pp. 30-36.
} 
descarbonización definidos para el horizonte 2030 y 2050 son muy ambiciosos y apuestan por acometer una transición energética basada en la reducción de gases de efecto invernadero y, en especial, en la disminución del consumo de energía de origen fósil. Todos estos objetivos pueden localizarse en el recientemente aprobado Paquete de Energía Limpia, también denominado como "Paquete de Invierno Energético"). Este paquete lo integran una serie de medidas legislativas que persiguen alcanzar los objetivos climáticos internacionales que se suscribieron en la Cumbre de París de 2015 (COP21) ${ }^{6}$, cuyo acuerdo central consistió en mantener el aumento de la temperatura media global por debajo de $1.5^{\circ} \mathrm{C}$ de incremento sobre la temperatura preindustrial. Sin embargo, el IPCC - Intergovernmental Panel on Climate Change-, tal y como se le reclamó en la Cumbre de París, emitió un informe ${ }^{7}$ donde se subrayaba que las expectativas de cumplimiento del objetivo señalado no eran en ningún caso positivas.

En este contexto, España ha definido una hoja de ruta hacia una transición energética basada en el fomento de las energías renovables y la descarbonización. Destacadamente, se ha presentado, en febrero de 2019, el Marco Estratégico de Energía y Clima: una oportunidad para la modernización de la economía española y la creación de empleo. Se trata de un paquete de medidas que persigue un modelo sostenible medioambientalmente que logre la transformación de la economía española, en aras de lograr mayor seguridad energética y desarrollo tecnológico, así como un incremento del empleo industrial. En concreto, este marco estratégico lo integran: el anteproyecto de Ley de Cambio Climático y Transición Energética (que está pendiente de ser tramitado en sede parlamentaria, tras haber sido sometido previamente a información pública), el Plan Nacional Integrado de Energía y Clima (PNIEC) 2021-2030 y la Estrategia de Transición Justa. Así, se pone de manifiesto en todas estas iniciativas el decidido impulso de nuevas subastas que permitan acometer la construcción de al menos 3.000 MW de instalaciones renovables.

\footnotetext{
${ }^{6} 21^{\text {a }}$ Conferencia de las Partes de la Convención Marco de las Naciones Unidas sobre el Cambio Climático de 2015 (COP21/CMP11), celebrada entre el 30 de noviembre y el 11 de diciembre de 2015.

7 Intergovernmental Panel on Climate Change, "Global Warming of $1.5^{\circ} \mathrm{C}$ ", Summary for Policymakers, Working Group I Technical Support Unit, Switzerland, January 2019.
} 
Así pues, esta necesidad, de primer orden, de producir electricidad lleva aparejada un impacto medioambiental de grandes dimensiones en todo el mundo. De forma que, para poner freno a esta catastrófica situación, se convierte en imprescindible una mayor penetración de energías renovables en el sistema.

\section{El importante papel de las energías renovables}

El actual modelo energético aún presenta elevados niveles de producción eléctrica basados en recursos fósiles, lo que refleja, desde el punto de vista medioambiental, un escenario insostenible en el medio y largo plazo ${ }^{8}$.

Para hacer frente a este escenario es necesario desarrollar actuaciones sobre la demanda, dirigidas a disminuir los actuales niveles de consumo eléctrico a través del fomento de los instrumentos de ahorro y eficiencia energética ${ }^{9}$, lo que va a reducir notablemente la actividad de generación y, con ello, la contaminación que lleva aparejada. Asimismo, para poner freno a estos elevados niveles de contaminación, es necesario incidir sobre la oferta, potenciando la implantación efectiva de tecnologías de generación basadas en fuentes de energía renovables, y con ello contribuyendo a un modelo descarbonizado y bajo en emisiones de gases de efecto invernadero.

Las energías renovables contribuyen singularmente al cumplimiento de los objetivos de política energética definidos a nivel europeo, los cuales persiguen consolidar un mercado interior de la energía seguro, competitivo y sostenible medioambientalmente ${ }^{10}$. En estos términos se establece en el recientemente

\footnotetext{
${ }^{8}$ Abel Estoa Pérez, "La limitación de las ayudas de estado a las energías renovables: las nuevas directrices de la Comisión Europea y el caso español", en Revista Española de Derecho Europeo, num. 53, 2015, pp. 1-4.

${ }^{9}$ Sobre las distintas medidas adoptadas en materia de ahorro y eficiencia energética, véase Isabel González Ríos, "Régimen jurídico de la eficiencia y el ahorro energético", en Revista Jurídica de Navarra, núm. 50, 2010, pp. 171-208; Isabel González Ríos, "La mejora de la eficiencia energética en edificaciones del litoral (propuesta para una interpretación integrada de la legislación de costas y de la normativa sobre eficiencia energética)", en Revista Española de Derecho Administrativo, núm. 167, 2014, pp. 195-229; y Susana Galera Rodrigo, "Del ahorro de energía a la eficiencia energética: objetivos e instrumentos de las políticas europeas", en Revista de Derecho Urbanístico y Medio Ambiente, núm. 289, 2014, pp. 85-120.

${ }_{10}$ Masao Javier López Sako, "El reto de las energías renovables en el mercado energético", en Roberto Galán Vioque, Isabel González Ríos y Fernando López Ramón (dirs.), Derecho de las energías renovables y la eficiencia energética en el horizonte 2020, Thomson Reuters Aranzadi. Navarra, 2017, pp. 147-151 y José Francisco Alenza García, "Las energías renovables ante la
} 
aprobado Paquete de Energía Limpia, y en particular en la Directiva (UE) 2018/2001 del Parlamento Europeo y del Consejo, de 11 de diciembre de 2018, relativa al fomento del uso de energía procedente de fuentes renovables (en adelante, Directiva (UE) 2018/2001) ${ }^{11}$. La norma europea alude de forma expresa al necesario apoyo financiero que requieren las fuentes de energía renovables, promoviendo procedimientos abiertos, transparentes, competitivos y no discriminatorios; de forma que se eviten distorsiones del mercado.

Así pues, desde hace muchos años (y, en especial, desde el año 2004), el legislador ha ido configurando mecanismos de apoyo a la generación renovable, lo cual ha sido especialmente necesario en la fase inicial de implantación de estas tecnologías, cuando aún no eran suficientemente maduras ni competitivas en el mercado. Estas medidas de apoyo se definieron bajo el entendimiento de que el sector eléctrico no podía dejar de apoyar a tecnologías más caras, o incluso ineficientes desde el punto de vista económico, si ello contribuía a una mejora de la sostenibilidad ambiental ${ }^{12}$. Sin embargo, con el paso de los años, las ayudas o primas concedidas a estas tecnologías renovables han ido creando una deuda de grandes dimensiones -el denominado déficit de tarifa-13, provocando así importantes ajustes (creación de impuestos, reducciones de la retribución de las empresas reguladas y modificaciones de la estructura de peajes, entre otras) en el sistema eléctrico destinados a hacer frente a este déficit estructural del sistema.

En este contexto, es necesario configurar un modelo que promueva la implantación efectiva de tecnologías de producción basadas en fuentes de energía renovables, lo que pasa por definir un régimen fiscal adecuado que respete los principios de capacidad y prohibición de la confiscatoriedad. Con carácter general, es necesario que las distintas figuras impositivas contemplen

\footnotetext{
fugacidad legislativa: la mitificación de los principios de (in) seguridad jurídica y de (des) confianza legítima: [A propósito de la STC 270/2015 sobre el nuevo sistema retributivo de las energías renovables], en Actualidad Jurídica Ambiental, núm. 55, 2016, p. 5.

${ }^{11}$ DOUE núm. 328, de 21 de diciembre de 2018.

12 Manuel Campos Sánchez Bordona, "Regulación como finalidad distinta al derecho a la competencia", en Javier Guillén Caramés (dir.), Derecho de la competencia y regulación en la actividad de las Administraciones Públicas, Thomson Civitas. Navarra, 2011, pp. 85-87.

${ }_{13}$ Alejandro D. Leiva López, "Cambios de modelo retributivo de la generación renovable en España: la confianza del inversor frente al riesgo regulatorio", en Revista Española de Derecho Administrativo, núm. 188, 2017, pp. 141-143.
} 
incentivos para este tipo de tecnologías renovables, ya que su gran contribución a la lucha contra el cambio climático y a la sostenibilidad ambiental justificaría suficientemente la oportunidad de recibir bonificaciones o exenciones fiscales. Sobre esta necesaria finalidad medioambiental de los tributos, y en especial en relación con el IVPEE, nos vamos a referir en el presente trabajo.

\section{LA CREACIÓN DEL IVPEE}

\section{Marco normativo: la Ley $15 / 2012$}

Este impuesto estatal fue creado por la Ley 15/2012, de 27 de diciembre, de medidas fiscales para la sostenibilidad energética (en adelante, Ley 15/2012) ${ }^{14}$, que creó también otros dos impuestos energéticos: el impuesto sobre la producción de combustible nuclear gastado y residuos radiactivos resultantes de la generación de energía nucleoeléctrica y el impuesto sobre el almacenamiento de combustible nuclear gastado y residuos radiactivos en instalaciones centralizadas $^{15}$. En particular, el IVPEE grava la realización de actividades de producción e incorporación al sistema de energía eléctrica, y presenta un carácter directo y finalidad medioambiental, tal y como señala el preámbulo ${ }^{16}$ de la Ley 15/2012; si bien sobre tal carácter y finalidad nos pronunciamos más adelante en detalle.

\footnotetext{
${ }^{14}$ BOE núm. 312, de 28 de diciembre de 2012.

${ }^{15}$ Sobre esta materia véase Enrique Ortiz Calle, "Los impuestos energéticos de la Ley 15/2012: problemas comunitarios y constitucionales", en Estudios financieros. Revista de contabilidad y tributación: comentarios, casos prácticos, núm. 403, 2016, pp. 111-140.

${ }^{16}$ Con carácter general, sobre los fines medioambientales que se proyectan sobre las distintas medidas fiscales adoptadas, el preámbulo señala que «[...] El fundamento básico de esta Ley se residencia en el artículo 45 de la Constitución, precepto en el que la protección de nuestro medio ambiente se configura como uno de los principios rectores de las políticas sociales y económicas. Por ello, uno de los ejes de esta reforma tributaria será la internalización de los costes medioambientales derivados de la producción de la energía eléctrica y del almacenamiento del combustible nuclear gastado o de los residuos radiactivos. De esta forma, la Ley ha de servir de estímulo para mejorar nuestros niveles de eficiencia energética a la vez que permiten asegurar una mejor gestión de los recursos naturales y seguir avanzando en el nuevo modelo de desarrollo sostenible, tanto desde el punto de vista económico y social, como medioambiental. La presente reforma contribuye además a la integración de las políticas medioambientales en nuestro sistema tributario, en el cual tienen cabida tanto tributos específicamente ambientales, como la posibilidad de incorporar el elemento ambiental en otros tributos ya existentes».
} 
Esta norma introduce un listado de medidas de carácter tributario que busca armonizar el modelo fiscal vigente con un uso de los recursos energéticos adecuado y sostenible medioambientalmente, en sintonía con los principios básicos que rigen la política ambiental, energética y fiscal en la Unión Europea. Además, la apoyatura constitucional de esta ley reside en el artículo 45 de la Constitución Española, en tanto promueve la protección del medioambiente como uno de los principios más destacados de la política social y económica. En particular, con la creación del IVPEE se busca internalizar los costes medioambientales derivados de la generación de energía eléctrica, así como también pretende servir de estímulo para contribuir a la mejora de los niveles de eficiencia energética y, a su vez, garantizar una óptima gestiónç de los recursos naturales, avanzando con ello hacia un modelo de desarrollo sostenible desde el punto de vista medioambiental, social y económico ${ }^{17}$.

Por tanto, observamos cómo la creación de este impuesto energético busca, aparentemente, financiar determinados costes asociados al sistema eléctrico vinculados a fines de eficiencia y ahorro energético, así como también persigue fomentar las tecnologías de generación basadas en fuentes de energía renovable. Sin embargo, esta pretendida finalidad medioambiental ha quedado en entredicho, como ponemos de manifiesto en el presente trabajo.

\section{Concepto y naturaleza jurídica}

El preámbulo de la Ley 15/2012 atribuye al IVPEE un carácter directo y una naturaleza real. A pesar de ello, entendemos que no cabe apreciar este carácter directo en relación con aquellos contribuyentes que utilizan fuentes de energía renovable para generar la electricidad, y en concreto aquellos que están acogidos al régimen de ayudas previsto para este tipo de tecnologías; esto es, a la denominada «retribución específica» ${ }^{18}$. Nos referimos a aquellos generadores

\footnotetext{
17 Pablo Renieblas Dorado, "Impuesto sobre el Valor de la Producción de Energía Eléctrica (IVPEE), base imponible y cálculo de pagos fraccionados, aplicación del criterio de devengo o el criterio de caja: Resolución del Tribunal Económico-Administrativo Central de 18 de septiembre de 2019", en Carta Tributaria. Revista de Opinión, núm. 61, 2020, pp. 2-4.

${ }^{18}$ A mayor abundamiento sobre este régimen de primas denominado «retribución específica», véase Alejandro D. Leiva López "El sector fotovoltaico frente a las reformas regulatorias en
} 
que reciben una retribución primada por estar acogidos al Real Decreto 413/2014, de 6 de junio, por el que se regula la actividad de producción de energía eléctrica a partir de fuentes de energía renovables (en adelante, RD $413 / 2014)^{19}$ y a la Orden IET/1045/2014, por la que se aprueban los parámetros retributivos de las instalaciones tipo aplicables a determinadas instalaciones de producción de energía eléctrica a partir de fuentes de energía renovables, cogeneración y residuos (en adelante, Orden IET/1045/2014) 20.

Y esto es así habida cuenta de que, para este tipo de generadores renovables, el IVPEE lo termina pagando, parcialmente, el consumidor final en su factura eléctrica; lo que pone de manifiesto que nos encontramos ante un impuesto indirecto. EI IVPEE se devuelve parcialmente al generador renovable acogido a «retribución específica», lo que se hace a través del concepto de "coste de operación", siendo esta prima soportada por todos los consumidores en la factura eléctrica, en la parte destinada a otros costes del sistema. Cabe subrayar que esta devolución no operará para los generadores renovables que no estén acogidos al modelo de primas, así como tampoco para aquellos generadores no renovables (centrales nucleares y térmicas).

Así pues, el admitir que el IVPEE es un impuesto indirecto va a tener implicaciones jurídicas muy relevantes, ya que la normativa europea viene exigiendo una finalidad medioambiental para aquellos impuestos indirectos que graven un producto ya sujeto a impuestos especiales; como sucede en este caso con la electricidad. Sobre estas implicaciones jurídicas nos vamos a referir en adelante.

\section{Hecho imponible. La posible existencia de doble imposición}

\footnotetext{
materia de ayudas a la producción de electricidad basada en fuentes de energía renovables", en Revista General de Derecho Administrativo, núm. 49, 2018, pp. 1-32; Inmaculada Revuelta Pérez, "Estándar del inversor prudente y confianza legítima", en Revista de Administración Pública, núm. 208, 2019, pp. 403-430; y Tomás de la Quadra-Salcedo y Fernández del Castillo, "Riesgo regulatorio y contractualización de la regulación por operadores y poderes públicos", en Juan Castro-Gil Amigo (coord.), Riesgo regulatorio en las energías renovables, Thomson Reuters Aranzadi. Navarra, 2015, pp. 29-81.

${ }^{19}$ BOE núm. 140, de 10 de junio de 2014.

${ }^{20}$ BOE núm. 150, de 20 de junio de 2014.
} 
El hecho imponible del IVPEE es la generación e incorporación al sistema de energía eléctrica, medida en barras de central. Así, en su base imponible se incluye el importe total que percibe el contribuyente por esa producción e incorporación de energía eléctrica al sistema.

En este orden de cosas, podríamos estar ante una doble imposición, habida cuenta de que esta materia imponible ya se contempla en el Impuesto sobre Actividades Económicas (en adelante, IAE), el cual grava el ejercicio de actividades empresariales, profesionales 0 artísticas desarrolladas por personas físicas o jurídicas. Sin embargo, si observamos la procedencia de los impuestos que concurren, estatal (IVPEE) y local (IAE), podemos descartar que pueda existir doble imposición, en tanto no concurre ningún impuesto de carácter autonómico, como viene exigiendo la Ley Orgánica 8/1980, de 22 de septiembre, de financiación de las Comunidades Autónomas (en adelante, LOFCA). Sobre este punto profundizamos en el epígrafe tercero.

\section{Circunstancias que motivaron su adopción: la situación deficitaria del sistema eléctrico español}

El denominado déficit de tarifa de que adolece el sistema eléctrico español justificó suficientemente la oportunidad de adopción del IVPEE. Este déficit consiste en un desajuste producido entre los ingresos y los costes reales del sistema ${ }^{21}$. Ello tiene lugar cuando los ingresos totales que se recaudan del consumidor a través de los precios regulados no son suficientes para satisfacer los costes reales que se asocian a esos precios regulados (entre estos costes destacan los asociados a las infraestructuras de red eléctrica o los necesarios para subvencionar la energía eléctrica de procedencia renovable) ${ }^{22}$. Este desajuste ha acontecido durante un periodo largo de tiempo (periodo 2000-

\footnotetext{
${ }^{21}$ Fernando Lasheras García y Sergio Arteta Arnaiz, "El déficit de tarifa y las reformas para corregirlo. El punto de vista comunitario", en Cuadernos de Energía, núm. 43, 2014, pp. 32-33.

${ }^{22}$ Véase Pedro Marín Uribe, "El déficit de tarifa", en Cuadernos de Energía, núm. 25, 2009, p. 33; Silvestre Arana y Álvaro Valle, "Déficit de tarifa. Retrospectiva y futuro de su regulación", en Cuadernos de Energía, núm. 34, 2012, p. 14; y Rafael Mateu de Ros Cerezo, "El déficit de la tarifa eléctrica: origen y regulación por el derecho positivo", en Fernando Becker Zuazua, Luis María Cazorla Prieto, Julián Martínez-Simancas Sánchez y José Manuel Sala Arquer (coord.), Tratado de regulación del sector eléctrico, vol. 1 (aspectos jurídicos), Thomson Reuters Aranzadi. Navarra, 2009.
} 
2013), lo que ha cristalizado en un déficit tarifario acumulado de grandes dimensiones. A partir de 2014 se comienzan a registrar superávits, pero hoy en día estos son insuficientes para cubrir todo el déficit acumulado del sistema.

Estos desajustes son la consecuencia directa de los numerosos errores de estimación de costes que han acontecido durante muchos años, ya que esos precios regulados que paga el consumidor se fijan en base a una estimación de costes a futuro. Asimismo, este déficit de tarifa lo han provocado las decisiones de política energética y económica que han adoptado los distintos Gobiernos, y en especial cabe subrayar el importante desajuste provocado por las generosas convocatorias de primas para generadores renovables que tuvieron lugar durante el periodo 2004-201323; las cuales provocaron que durante muchos años los ingresos que se obtenían con las tarifas pagadas por los consumidores fuesen insuficientes para soportar las primas que debían retribuirse a los generadores renovables. En definitiva, todo ello ha dado lugar a un déficit de tarifa acumulado que ha llegado a alcanzar la cifra de los $30.000 \mathrm{M} €^{24}$, lo que sucedió al finalizar el año 2013. A partir de 2014 comenzó a producirse un superávit, y hasta 2018 se han acumulado cerca de $2.000 \mathrm{M} €$ en positivo ${ }^{25}$. Estas partidas de superávit han sido destinadas cada año a reducir los desajustes de ejercicios anteriores, tal como exige el artículo 19.4 de la Ley 24/2013, de 26 de diciembre, del Sector Eléctrico (en adelante, LSE) ${ }^{26}$, pero ello es aún insuficiente para cubrir la ingente suma de déficit de tarifa acumulado durante el periodo anterior. Si bien cabe destacar que en la actualidad, gracias a las anualidades del déficit y con la compensación de los superávits, el déficit acumulado se ha conseguido reducir hasta casi la mitad de esos $30.000 \mathrm{M} €$ que arrojaba a finales de $2013^{27}$.

\footnotetext{
${ }^{23}$ Sobre estas convocatorias de ayudas véase Leiva López, "Cambios de ..." cit., pp. 138-144. 24 Abel Estoa Pérez y Mariano Bacigalupo Saggese, "La financiación del déficit del sistema eléctrico: jurisprudencia reciente y regulación en la nueva ley del sector", en Revista de Derecho de la Competencia y la Distribución, núm. 14, 2014, pp. 159-161.

${ }^{25}$ Sobre el balance de déficit/superávit del periodo 2000-2018, veáse el "Acuerdo por el que se emite informe sobre el estado actual de la deuda del sistema eléctrico", Expediente INF/DE/002/20, Sala de Supervisión Regulatoria, Comisión Nacional de los Mercados y la Competencia. Madrid, 14 de enero de 2020, pp. 6-13.

${ }^{26}$ BOE núm. 310, de 27 de diciembre de 2013.

${ }^{27}$ CNMC, "Acuerdo por el que..." cit.
} 
En este orden de cosas, el IVPEE busca aumentar la recaudación y con ello hacer frente a ese desajuste mencionado entre ingresos y costes. Cabe subrayar que no es el único instrumento legal destinado a tal fin, ya que han existido y existen otros que, por ejemplo, han aplicado reducciones de la tasa de retribución financiera de los generadores renovables y de las empresas reguladas (transportistas y distribuidores) ${ }^{28}$. Así pues, entendemos que el fin único, y legítimo, del IVPEE es el estrictamente recaudatorio, sin que pueda observarse con claridad otro fin de carácter extrafiscal. Es necesario utilizar instrumentos legales para resolver cuanto antes el problema del déficit tarifario, si bien es cierto que, a nuestro juicio, existe otra vía menos controvertida que la creación de un impuesto que recae sobre un hecho imponible ya gravado: sacar las cantidades relativas al déficit de tarifa acumulado a Presupuestos Generales del Estado.

\section{La suspensión del IVPEE. Causas y efectos}

La publicación del Real Decreto-ley 15/2018, de 5 de octubre, de medidas urgentes para la transición energética y la protección de los consumidores (en adelante, RDL 15/2018)29 trajo consigo la exoneración del IVPEE, durante seis meses, para los contribuyentes que generaban electricidad y la incorporaban al sistema. Esta suspensión coincidió con los meses de mayor demanda eléctrica y, a su vez, mayores precios en el Pool. Esta medida buscaba atenuar el impacto económico negativo que podrían suponer estos precios para los hogares que se encuentran en situación de pobreza energética; esto es, en una situación de vulnerabilidad que les impide satisfacer las necesidades básicas de suministro eléctrico, como consecuencia de unos niveles de ingresos escasos y/o de una vivienda infradotada de instrumentos de eficiencia energética. Si bien cabe destacar que existen otras medidas específicas dirigidas a la protección de los consumidores vulnerables o que padecen pobreza energética, las cuales

\footnotetext{
${ }^{28}$ Sobre las recientes modificaciones a la baja de la retribución de las empresas reguladas del sector eléctrico, véase Marina Serrano González, "Nueva regulación de la distribución de energía eléctrica en las Circulares de la Comisión Nacional de los Mercados y la Competencia", en Cuadernos de Energía, núm. 60, 2019, pp. 26-31.

${ }^{29}$ BOE núm. 242, de 05 de octubre, de medidas urgentes para la transición energética y la protección de los consumidores.
} 
constituyen una política pública esencial en nuestra sociedad (como, por ejemplo, el bono social) $)^{30}$.

Esta suspensión operada a través del RDL 15/2018 fue muy relevante a los efectos de poner en duda el carácter directo que la Ley 15/2012 le atribuía al IVPEE. En este sentido, si la suspensión del impuesto buscaba proteger al consumidor, se estaría admitiendo que su carácter es, en realidad, indirecto. Como consecuencia, cabría observar que el IVPEE podría estar vulnerando la normativa europea, en tanto ésta exige que todo impuesto indirecto que grave un producto ya sujeto a impuestos especiales, debe presentar una finalidad extrafiscal. Y, sin embargo, aquí existen serias dudas de que tal finalidad exista.

Además, el RDL 15/2018 exigía al Gobierno la adopción de una estrategia nacional en relación con este fenómeno de la pobreza energética, lo que terminó viendo luz verde en Consejo de Ministros de abril de 2019, a través de la aprobación de la Estrategia Nacional contra la Pobreza Energética 2019-2024. Este documento contiene medidas estructurales prevista para el corto, medio y largo plazo. El cumplimiento de esta estrategia será supervisado por el Instituto para la Diversificación y el Ahorro de la Energía (IDAE). Cabe subrayar que para la elaboración del texto se ha contado con las Comunidades Autónomas, con las entidades locales y con los agentes y colectivos sociales, así como también se realizó una consulta pública que recibió más de cien aportaciones.

\section{LA POSIBLE EXISTENCIA DE DOBLE IMPOSICIÓN ENTRE EL IVPEE Y EL IAE}

\section{Posiciones a favor de la existencia de doble imposición}

EI IVPEE podría estar recayendo en la misma materia imponible que el IAE, ya que se gravan los importes totales que perciben los contribuyentes por la actividad empresarial que desarrollan. En otras palabras, el IVPEE y el IAE

30 Véase Íñigo Del Guayo Castiella, "Consumidores vulnerables en el sector eléctrico, lucha contra la pobreza energética y el bono social", en Revista de Administración Pública, núm. 203, 2017, p.346. 
estarían recayendo sobre una manifestación idéntica de riqueza de los contribuyentes.

Con carácter general, los generadores de electricidad han considerado que existe una doble imposición, en la medida en que nos encontramos con un tributo (IVPEE) que recae sobre una materia imponible ya gravada por otro impuesto $(\mathrm{IAE})$, sin que exista una finalidad extrafiscal que lo justifique. En este sentido, defienden que a pesar de que la Ley 15/2012 dice otorgar al IVPEE una finalidad medioambiental, y por lo tanto extrafiscal, esto no se desprende de los elementos del tributo. No existiría este fin medioambiental en la medida en que no se aprecia una diferenciación entre tecnologías de generación en función de su grado de impacto ambiental, ya que se prevé la misma carga fiscal para todas ellas. Así, el gravamen del $7 \%$ es de aplicación para todos los generadores, independientemente de la tecnología, más o menos contaminante, que empleen y del tamaño que representen.

Esta posición fue también la mantenida por el Tribunal Supremo en sus autos de 14 de junio de 2016 y de 10 de enero de 2018, lo que le llevó a plantear las correspondientes cuestiones de inconstitucionalidad (con números 4177-2016; 4179-2016; y 503-2018). El alto tribunal sostiene que de existir una finalidad medioambiental, ello debería reflejarse de forma inequívoca en la estructura del impuesto. No resultando suficiente introducir en los elementos del tributo ciertos incentivos o estímulos de determinadas conductas, como ya viene sosteniendo el Tribunal Constitucional (STC 112/2012, de 5 de junio) ${ }^{31}$. Es este punto, destaca la STC 289/2000, de 30 de noviembre ${ }^{32}$, en tanto se pronuncia sobre la inexistencia de finalidad medioambiental en el Impuesto autonómico sobre instalaciones que incidan en el medio ambiente ${ }^{33}$. Así pues, en el caso que nos ocupa, los contribuyentes estarían soportando el mismo gravamen independientemente del daño ambiental que provoquen sus instalaciones, y por

\footnotetext{
${ }^{31}$ BOE núm. 159, de 04 de julio de 2012.

32 BOE núm. 4, de 04 de enero de 2001.

33 "(...) Estamos, pues, en presencia de un tributo que no grava directamente la actividad contaminante, sino la titularidad de unas determinadas instalaciones $y$, como veremos de inmediato, el hecho de que el valor de esas instalaciones se calcule mediante la capitalización de los ingresos no trasmuta lo que es impuesto sobre unos elementos patrimoniales en un impuesto sobre actividades contaminantes (...)".
} 
tanto el IVPEE no estaría teniendo en cuenta que hay unas instalaciones de generación más contaminantes que otras (las fósiles respecto de las renovables), así como tampoco se estaría tomando en consideración que hay unas instalaciones de generación que provocan mayores necesidades de ampliación y refuerzo en las redes de electricidad que otras (lo que depende de la potencia de generación instalada en cada caso), con el consiguiente daño ambiental que ello comporta. Por tanto, solo cabría observar una finalidad estrictamente recaudatoria o fiscal, lo que estaría poniendo de manifiesto la existencia de doble imposición. Una finalidad recaudatoria que puede existir, pero que, en todo caso, debe venir acompañada de una finalidad extrafiscal (en este caso ambiental). Todo ello viene reforzado por el Informe de la Comisión de expertos para la reforma del sistema tributario español de 2014, el cual estableció que el IVPEE no puede identificarse con la definición europea de "impuesto ambiental", ya que su base imponible no presenta una magnitud no monetaria (no recaudatoria), así como tampoco existen elementos estructurales que modelen la carga tributaria en función del grado de desarrollo de comportamientos por parte del contribuyente conducentes a una más óptima conservación del entorno medioambiental ${ }^{34}$. En definitiva, si admitimos que no existe tal finalidad medioambiental, cabría afirmar el IVPEE no estaría proyectando, en ningún caso, el principio de "quien contamina, paga".

Además, esta falta de diferenciación entre tecnologías de generación también podría estar vulnerando principios generales del derecho consagrados. En particular, no se estaría teniendo en cuenta que hay generadores renovables que en 2012 no podían acudir a mercado, por presentar sus tecnologías menor madurez, y que, por tanto, menos aún podrían soportar un impuesto adicional, como el IVPEE. Desde este punto de vista, la configuración del IVPEE, sin diferenciación por tecnologías, podría estar vulnerando los principios de seguridad jurídica y de confianza legítima. Más bien, se debió tener en cuenta este aspecto a la hora de definir el gravamen, de manera que no todas las tecnologías soportasen la misma carga fiscal. Sin embargo, sobre esta cuestión

\footnotetext{
${ }^{34}$ Informe de la Comisión de Expertos para la reforma del sistema tributario español, propuesta núm. 89. Madrid, febrero de 2014, pp. 325-328.
} 
se pronunció el Tribunal Constitucional en su sentencia 183/2014 ${ }^{35}$, concluyendo que los necesarios ajustes que los generadores renovables sujetos a prima debían acometer como consecuencia de la aparición del IVPEE, estaban dentro de unos márgenes razonables de previsibilidad compatibles, en todo caso, con los principios de confianza legítima y seguridad jurídica ${ }^{36}$.

\section{Pronunciamientos del Tribunal Constitucional}

Como hemos señalado, el Tribunal Supremo planteó varias cuestiones de inconstitucionalidad. En concreto, estos se plantearon en el marco de los recursos de casación interpuestos, en 2016, por la patronal eléctrica UNESA (ahora denominada Asociación Empresarial de la Industria Eléctrica, AELEC) y, en 2016 y 2018, por Iberdrola Generación S.A.U. Estos recursos de casación se interpusieron contra sentencias desestimatorias de la Audiencia Nacional que se pronunciaron sobre las impugnaciones de la Orden HAP/703/2013, de 29 de abril, por la que se aprueba el modelo 583 "Impuesto sobre el Valor de la Producción de la Energía Eléctrica. Autoliquidación y Pagos Fraccionados", y se establecen la forma y procedimiento para su presentación ${ }^{37}$.

En este contexto, el Tribunal Constitucional inadmitió a trámite -a través de los Autos 202/2016, de 13 de diciembre; 204/2016, de 13 de diciembre; y 69/2018, de 20 de junio ${ }^{38}$ - todas estas cuestiones de inconstitucionalidad planteadas en 2016 y 2018. El alto tribunal ha subrayado que es posible imponer dos gravámenes distintos a una misma actividad, sin que la inexistencia de

\footnotetext{
${ }^{35}$ BOE núm. 293, de 04 de diciembre de 2014.

36 "[...] La demanda denuncia el grave riesgo que se origina a la rentabilidad de las inversiones renovables llevadas a cabo por los promotores que ven así mermados los ingresos de unos proyectos iniciados bajo unas condiciones financieras distintas a las actuales, pero no ofrece término de comparación alguno a partir del cual discutir una presunta diferencia en la ley. Las razones que ofrece son de pura política legislativa y no de constitucionalidad y, por tanto, ajenas a este proceso. Tampoco es posible apreciar una vulneración de la confianza de los ciudadanos que hayan ajustado su conducta económica a la legislación vigente pues, además de entrar dentro de los márgenes razonables de previsibilidad atendiendo a la política fiscal que se viene llevando a cabo, la reforma que propone la Ley 15/2012 carece de retroactividad alguna [...] entre las exigencias de la seguridad jurídica no se incluye derecho alguno a la inalterabilidad del régimen fiscal'.

${ }^{37}$ BOE núm. 103, de 30 de abril de 2013.

${ }^{38}$ BOE núm. 179, de 25 de julio de 2018.
} 
finalidad medioambiental (extrafiscal) convierta al impuesto en inconstitucional ${ }^{39}$. El motivo de ello radica en que solo cabe observar doble imposición cuando, según establece el artículo 6 de la LOFCA, concurre un impuesto autonómico con un impuesto estatal o local; y no, como es el caso, cuando concurren un impuesto estatal (IVPEE) y un impuesto local (IAE). Así pues, al no darse esta circunstancia, entiende el Tribunal que no cabría entrar a valorar si existe o no finalidad medioambiental, a los efectos de calificar una posible doble imposición. Para el Tribunal Constitucional, la posible ausencia de finalidad extrafiscal -que no entra a valorar- no habría sido suficiente para tachar como inconstitucional el IVPEE. Por tanto, en la medida en que se descarta la posible doble imposición, solo cabría plantearse -como dispone la STC 242/2004, de 16 de diciembre ${ }^{40}$ la posible ilegitimidad del IVPEE desde el punto de vista del incumplimiento de los principios de capacidad económica y de interdicción de la confiscatoriedad (ex artículo 31.1 CE). En este sentido, el alto tribunal ha entendido (ATC 69/2018) ${ }^{41}$, por un lado, que el IVPEE grava un hecho imponible -generación de energía eléctrica- que manifiesta suficiente capacidad económica, y, por otro, que el Tribunal Supremo no justifica suficientemente en su auto (ATS de 10 de enero de 2018) el posible alcance confiscatorio del impuesto ${ }^{42}$. De haber existido este alcance confiscatorio tendría que haberse puesto de manifiesto que el tributo

\footnotetext{
39 Véase también sobre esta materia, Alberto García Moreno, "El Impuesto sobre el Valor de la Producción de Energía Eléctrica (IVPEE) y el Impuesto sobre Actividades Económicas. Una doble imposición constitucional", en Carta tributaria. Revista de opinión, núm. 43, 2018, p. 1-2. ${ }^{40}$ BOE núm. 18, de 21 de enero de 2005.

41 A mayor abundamiento sobre este auto cabe destacar Daniel Casas Agudo, "Sobre la legitimidad constitucional de la concurrencia del Impuesto sobre el Valor de la Producción de la Energía Eléctrica y el Impuesto sobre Actividades Económicas. A propósito del Auto del Tribunal Constitucional núm. 69/2018, de 20 de junio", en Nueva fiscalidad, núm. 4, 2018, pp. 213-223.

42 "[...] no solo debe tenerse en cuenta "la dificultad técnica que supone determinar, en abstracto, si del régimen legal de un tributo pueden derivarse efectos confiscatorios, sobre todo cuando la interpretación que haya de darse a este principio de no confiscación en materia fiscal dista de ser una cuestión doctrinalmente pacífica" [STC 14/1998, de 22 de enero, FJ 11 B)], sino que en los casos en que el Tribunal ha debido analizar esta tacha siempre ha exigido a quien la denuncia la aportación de los correspondientes datos o argumentos que la sustenten.

En el presente caso ni en el Auto por el que se promueve la cuestión ni, lo que es más revelador, en el recurso de Iberdrola Generación, S.A.U., que da lugar a la misma se aporta dato o argumento alguno dirigido a fundamentar que el impuesto sobre el valor de la producción de la energía eléctrica tenga alcance confiscatorio, lo que nos conduce a descartar esta imputación. No se encuentran razones para sostener que la regulación del impuesto sobre el valor de la producción de la energía eléctrica vulnere el artículo 31.1 CE, pudiendo reiterarse la afirmación de la STC 183/2014, que analizó esta figura desde la óptica de los artículos 14 y 9.3 CE, de que la creación y diseño de este tributo "responde a una opción del legislador» que "Cuenta con un amplio margen para el establecimiento y configuración del tributo" (FJ 3), siempre que respete los principios constitucionales, sin que ninguno de los invocados pueda considerarse quebrantado"
} 
priva al contribuyente de sus rentas y propiedades, agotando así la riqueza imponible (SSTC 150/1990, de 4 de octubre ${ }^{43}$, 14/1998, de 22 de enero ${ }^{44}$ y 242/1999, de 21 de diciembre ${ }^{45}$; y AATC 71/2008, de 26 de febrero ${ }^{46}, 120 / 2008$, de 6 de mayo y 342/2008, de 28 de octubre).

A nuestro juicio, si hubiese concurrido con el IVPEE un impuesto autonómico, lo que habría justificado el entrar a valorar la posible existencia de finalidad medioambiental, podría haberse suscitado un intenso debate en cuanto a si la devolución parcial del IVPEE, que reciben los generadores renovables acogidos a prima, podría considerarse un trato diferenciado respecto a otras tecnologías $y$, con ello, un posible incentivo para las empresas a producir con energía limpia; esto es, podría haberse confirmado igualmente la legitimidad del IVPEE, en tanto estaría presentando un fin medioambiental (extrafiscal). Sin embargo, esta tesis habría perdido fuerza si tenemos en cuenta que hay también generadores renovables que van directamente a mercado y que, al no recibir «retribución específica» (prima), no estarían viendo compensado el pago del IVPEE. Por tanto, estos generadores renovables estarían soportando el mismo gravamen (7\%) que las plantas de generación tradicionales (como son aquellas que obtienen la energía de la combustión de combustibles fósiles -carbón y gas-), las cuales proyectan mayores niveles de contaminación. Por otro lado, tampoco existiría un trato diferenciador en la aplicación del impuesto, en la medida en que éste no atiende al nivel de daño ambiental que provoca cada instalación en función de su tamaño, lo que debía tenerse en cuenta habida cuenta de que a mayores dimensiones de la planta de generación, mayores niveles de refuerzos y ampliaciones de infraestructuras de red se necesitan, con el consiguiente daño ambiental que ello comporta. Así pues, por todos estos motivos, este impuesto, para lograr la pretendida finalidad ambiental, tendría que haber contemplado un trato diferenciador entre las distintas plantas de generación, en función del tipo de tecnología que emplean y del tamaño de sus instalaciones. Dicho esto, vemos complicado que se sostuviese una tesis a favor de la existencia de finalidad medioambiental que justificase la adopción del IVPEE. En todo caso, insistimos,

\footnotetext{
43 BOE núm. 266, de 06 de noviembre de 1990.

44 BOE núm. 47, de 24 de febrero de 1998.

45 BOE núm. 17, de 20 de enero de 2000.

46 BOE núm. 76, de 28 de marzo de 2008.
} 
solo habría tenido cabida entrar a analizar este punto si el impuesto con el que concurre el IVPEE fuese autonómico, lo que no sucede, al ser el IAE un impuesto local.

En este orden de cosas, cabe destacar que existen más concurrencias legítimas entre impuestos estatales y locales que gravan un mismo hecho imponible, y que están consolidadas en nuestro ordenamiento jurídico. Nos encontramos, así, con el Impuesto sobre el Patrimonio (estatal) y su concurrencia con el Impuesto sobre Bienes Inmuebles o con el Impuesto sobre Vehículos de Tracción Mecánica (locales); y también con el Impuesto sobre la Renta de las Personas Físicas o el Impuesto de Sociedades (estatales) en concurrencia con el Impuesto sobre Actividades Económicas o el Impuesto sobre el Valor de los Terrenos de Naturaleza Urbana (locales). Por tanto, en estos casos no es necesario que presenten un fin extrafiscal a los efectos de calificar una posible doble imposición, como ya ha manifestado el Tribunal Constitucional en numerosas ocasiones ${ }^{47}$.

\section{LA COMPATIBILIDAD ENTRE EL IVPEE Y EL DERECHO DE LA UNIÓN EUROPEA}

\section{EI IVPEE como impuesto indirecto}

Como ya hemos señalado, la pretensión de la Ley de creación del IVPEE es atribuirle carácter directo. Ello cabe apreciarse en relación con las centrales de generación tradicionales (nuclear, térmica...), ya que sumen la carga tributaria de forma íntegra. Sin embargo, no sucede de igual forma con las plantas de generación basadas en fuentes de energías renovables, y en concreto con aquellas que acuden a un régimen retributivo primado. Este tipo de tecnologías van a recibir la devolución parcial del IVPEE a través de la denominada «retribución específica» (acogidos al RD 413/2014 y a la Orden IET/1045/2014), y en concreto este impuesto computa como "coste de operación" de la instalación. Por tanto, teniendo en cuenta que esta «retribución específica» la termina soportando el consumidor final en la factura eléctrica (de forma repartida

\footnotetext{
47 Véase, entre otros pronunciamientos, la STC 233/1999, de 16 de diciembre (BOE núm. 17, de 20 de enero de 2000) y el ATC 261/2003, de 15 de julio.
} 
entre el Término Potencia -fijo- y el Término Energía -variable-), cabe afirmar que el IVPEE también lo estaría sufragando, al menos parcialmente, este consumidor. Si bien cabe significar que los generadores renovables que no estén acogidos a este régimen primado, sí asumirían la carga fiscal total del IVPEE.

Además, la propia doctrina del TJUE (Sentencia de 1 de octubre de 2015, asunto C-606-13; y Sentencia de 20 de septiembre de 2017, asuntos acumulados C-215/16, C-216/16, C-220/16 y C-221/16) nos vendría a confirmar tal calificación, ya que establece que cuando un hecho imponible esté vinculado a la producción y venta de energía eléctrica (en concreto, en el artículo 6.1 Ley $15 / 2012$, se observa que la base imponible recoge el importe total recibido por la producción e incorporación al sistema de energía eléctrica medida en barras de central) y el coste del impuesto sea trasladado al consumidor final, estamos ante un gravamen indirecto sobre la electricidad; esto es, ante un impuesto indirecto. $Y$ aún más clarificador, a los efectos de calificar el IVPEE como impuesto indirecto, es el hecho de que la suspensión del IVPEE por periodo de seis meses (según estableció el RDL 15/2018) encontrase su justificación en la necesidad de proteger a los consumidores, y en especial habida cuenta la situación de especial vulnerabilidad (pobreza energética) en la que se encuentran muchos de ellos ${ }^{48}$.

En este orden de cosas, en relación con los generadores renovables sujetos a prima, el IVPEE debería tener la consideración de impuesto indirecto, lo que va a tener implicaciones jurídicas muy relevantes; como vemos a continuación.

\section{Normativa europea afectada}

\footnotetext{
${ }^{48}$ A mayor abundamiento sobre la situación de estos colectivos vulnerables y sobre los retos y propuestas que actualmente están siendo objeto de debate, véase Eva Arenas Pinilla, Roberto Barrella, María Burzaco Samper, Pedro José Cabrera Cabrera, Efraim Centeno Hernáez, M.E. Escribano Alonso, Javier Wenceslao Ibáñez Jiménez, Pedro Linares Llamas, José Carlos Romero Mora y Pablo Sanz Bayón, "La pobreza energética en España", en Agustín Blanco Martín, Antonio Manuel Chueca Sánchez, José Antonio López Ruiz y Sebastián Mora Rosado (coord.), Informe España 2019, Ed. Universidad Pontificia Comillas. Salamanca, 2019, pp. 176229.
} 
El hecho de que el IVPEE pueda ser considerado un impuesto indirecto, y no un impuesto directo -como señala la Ley 15/2012-, va a plantear dudas acerca de su compatibilidad con la normativa europea de aplicación ${ }^{49}$.

La Directiva (UE) 2020/262 del Consejo, de 19 de diciembre de 2019, por la que se establece el régimen general de los impuestos especiales (en adelante, Directiva 2020/262) $)^{50}$ establece, en el apartado segundo de su artículo primero, que «Los Estados miembros podrán imponer a los productos sujetos a impuestos especiales otros gravámenes indirectos con fines específicos (...)». Por tanto, según el tenor literal de la norma europea, el IVPEE, en tanto impuesto indirecto, debería presentar una finalidad específica; esto es, una finalidad extrafiscal (en este caso, medioambiental). A pesar de los intentos del legislador de atribuir finalidad medioambiental al IVPEE -señalando de forma expresa que busca armonizar el sistema fiscal con un uso respetuoso del medioambiente-, entendemos que esto no tiene lugar, ya que, en realidad, el fin único del impuesto es recaudatorio.

Cabe destacar que la Directiva 2020/262 es continuista con lo ya establecido en la Directiva 2008/118/CE del Consejo, de 16 de diciembre de 2008, relativa al régimen general de los impuestos especiales, y por la que se deroga la Directiva 92/12/CEE ${ }^{51}$. Siendo esta última la que ha servido de apoyo para plantear las cuestiones prejudiciales pertinentes.

\section{Acerca de la pretendida finalidad medioambiental del IVPEE}

A pesar de que la Ley 15/2012 atribuye finalidad medioambiental al IVPEE, consideramos que de ninguno de sus elementos se desprende tal fin. En otras palabras, no cabe apreciar un trato diferenciador hacia el contribuyente (plantas de generación) que atienda el mayor o menor grado de impacto ambiental que

\footnotetext{
${ }^{49}$ Sobre este punto véase, entre otros, Enrique Ortiz Calle, "Compatibilidad del impuesto sobre el valor de la producción de la energía eléctrica con el derecho de la Unión Europea", en Estudios financieros. Revista de contabilidad y tributación: Comentarios, casos prácticos, núm. 437-438, 2019, pp. 83-116.

50 DOUE núm. 58, de 27 de febrero de 2020.

${ }^{51}$ DOUE núm. 9, de 14 de enero de 2009.
} 
sus instalaciones provocan, siendo de aplicación el mismo gravamen para todas ellas (7\%). No se estaría teniendo en cuenta que hay unas plantas de generación (fósiles) que contaminan más que otras (renovables), así como tampoco que en función del tamaño de las instalaciones de generación, el daño ambiental va a ser de mayor o menor intensidad; ya que a mayor tamaño, mayores son las necesidades de refuerzo en las infraestructuras de red eléctrica y, por tanto, mayor es el impacto ambiental producido. Así pues, en relación con este impuesto, no estaría desplegando ninguna virtualidad el consagrado principio de "quien contamina, paga".

Solo cabría plantearse si el hecho de que las plantas de generación renovable obtengan una compensación parcial del IVPEE, a través de la retribución específica que reciben (prima), puede considerarse un beneficio fiscal para este tipo de instalaciones menos contaminantes. Pero lo cierto es que de ello no puede desprenderse que exista una finalidad medioambiental en sentido estricto, pues también existirán instalaciones renovables que no están acogidas al régimen primado, y que por tanto no verían compensado el pago del IVPEE, debiendo soportar la misma carga fiscal que una central tradicional fósil.

Dicho esto, no cabría observar que se den los fines específicos a que se refiere la Directiva 2020/262, y que justificarían la oportunidad de adoptar este gravamen sobre un producto ya sujeto a impuesto especial. Para que ello hubiese tenido lugar, habría sido necesario que en la estructura del impuesto se contemplase un trato diferenciador entre las distintas plantas de generación, que atendiese a la tecnología que emplean y a las necesidades de refuerzos de red que provocan en función de su tamaño.

\section{El planteamiento de cuestión prejudicial por parte del Tribunal Superior de Justicia de Valencia}

Los generadores que han solicitado rectificaciones de sus autoliquidaciones del IVPEE, para poder recuperar así los ingresos indebidos realizados a la AEAT, han obtenido en todos los casos la respuesta desestimatoria por parte de la 
Administración, de los tribunales económico-administrativos regionales y de los Tribunales Superiores de Justicia de las respectivas Comunidades Autónomas. Todo ello de conformidad con el procedimiento establecido en el artículo 32.5 LRJSP. Han sido numerosos los casos en que se ha reclamado de los Tribunales Superiores de Justicia que planteen cuestiones prejudiciales al TJUE, con motivo de la posible incompatibilidad entre el IVPEE y el Derecho de la Unión Europea, pero solo en una ocasión se ha atendido esta petición. Nos referimos al Auto del Tribunal Superior de Justicia de Valencia de 22 de febrero de 2019 (recurso número 1491/2017), sobre el asunto C-220/19. Este auto resuelve un recurso contencioso-administrativo interpuesto por la mercantil Promociones Oliva Park, S.L. contra la resolución de 28.09.2017 del Tribunal Económico Administrativo Regional de la Comunidad Valenciana, que desestima la reclamación 46/4439/17 planteada frente a la resolución de la Oficina Gestora de Impuestos Especiales de Valencia, desestimatoria de una solicitud de rectificación de las autoliquidaciones del IVPEE de los ejercicios 2013 a 2016

EI TSJ de Valencia señala en su auto que el IVPEE es, en realidad, un impuesto indirecto, ya que así lo admite explícitamente el propio RDL 15/2018, al contemplar una suspensión del impuesto con motivo de proteger a los consumidores más vulnerables ${ }^{52}$. Desde esta perspectiva, el IVPEE sería contrario a la Directiva 2008/118/CE, ya que estaríamos ante un impuesto indirecto que no contiene el fin específico o extrafiscal que exige la norma europea. El auto señala que se trata de un impuesto de carácter estrictamente recaudatorio, como así lo confirma la disposición adicional segunda de la Ley 15/2012, la cual establece que la recaudación del IVPEE irá destinada a financiar los costes del sistema eléctrico (fundamentalmente a sufragar el déficit de tarifa

\footnotetext{
52 "[...] el Gobierno ha aprobado el RDL 15/2018, de 5 de octubre, por el que se establece una exención transitoria en la aplicación del IVPEE, que exonera de su pago durante seis meses a los productores de energía incorporados al sistema eléctrico. Esta medida se ha adoptado en un mes en el que el precio de la electricidad había alcanzado sus máximos anuales, con la manifestada intención de reducir la factura eléctrica de los consumidores [...] la anterior información da una inicial causa para mantener la tesis de que nos encontramos no ante un impuesto directo, sino ante un impuesto indirecto, lo que conllevaría, en su caso, necesariamente a su anulación por incompatibilidad con la normativa europea sobre impuestos especiales, que prohíbe que el legislador nacional grave un producto ya gravado por un impuesto especial salvo que se justifique que dicho tributo obedece a fines específicos, esto es, que tiene carácter finalista $[\ldots]^{\prime}$.
} 
acumulado) ${ }^{53}$. Por tanto, en la línea ya defendida, el TSJ de Valencia descarta que en la estructura del IVPEE existan bonificaciones o exenciones que puedan dar lugar a una modulación de los comportamientos de los productores conducente a lograr un menor impacto ambiental ${ }^{54}$. De hecho, la base imponible del impuesto no se estaría vinculando al riesgo medioambiental o a la capacidad de contaminación que presenta cada contribuyente.

Además de tratarse de un impuesto contrario a la Directiva 2008/118/CE (en la actualidad, Directiva 2020/262), también estaría alejándose de las directrices sobre fomento de las energías renovables contenidas en la Directiva (UE) 2018/2001. Y ello en la medida en que el IVPEE no ofrece un trato diferenciador para cada tipo de tecnología, lo que debiera haberse contemplado en términos de una menor carga fiscal para aquellos generadores que utilicen fuentes de energía renovable. Solo cabría observar como medida de apoyo a las renovables el hecho de que éstas reciban la devolución parcial del IVPEE a través del concepto "coste de operación" contenido en su «retribución específica» (prima), aunque lo cierto es que no existiría tal devolución para aquellos generadores renovables que no están acogidos al régimen primado; por lo que no cabe apreciar un fin medioambiental en toda su extensión.

Por otro lado, también cabría apreciar que el IVPEE es contrario al Tratado de Funcionamiento de la Unión Europea (en adelante, TFUE) ${ }^{55}$. En particular, se podría estar vulnerando el principio de libre competencia entre empresas a que

\footnotetext{
53 "EI IVPEE incumple otra exigencia comunitaria, pues carece de un fin específico. La Ley 15/2012 anuncia en su preámbulo que el fin del IVPEE es la armonización del ordenamiento fiscal española con un uso más eficiente y respetuoso del medioambiente, pero no se aprecia una finalidad específica o extrafiscal para la creación de este impuesto, ya que la recaudación no va destinada a financiar políticas medioambientales concretas sino a reducir el "déficit de tarifa" que, según la Sentencia de la Audiencia Nacional de 30 de enero de 2013, confirmada por la Sentencia del Tribunal Supremo de 18 de noviembre de 2013, es en términos normativos la diferencia entre la recaudación por las tarifas reguladas que fija la Administración y que pagan los consumidores por sus suministros regulados y por las tarifas de acceso que se fijan en el mercado liberalizado y los costes reales asociados a dichas tarifas, teniendo por tanto una finalidad puramente recaudatoria".

54 "No se contemplan exenciones o bonificaciones atendiendo al comportamiento del sujeto pasivo, con independencia del uso que éste haga de la red eléctrica y su incidencia medioambiental. No existen beneficios fiscales a la producción de energía eléctrica de fuentes renovables, menos lesivas para el medio ambiente, o para quienes, por su volumen, fuente, intensidad o extensión del transporte y la distribución no tienen impacto ambiental relevante. Con ello se discrimina positivamente a quienes la producen a partir de fuentes no renovables y mucho más dañinas al medio ambiente".

${ }^{55}$ DOUE núm. 326, de 26 de octubre de 2012.
} 
se refiere el artículo 107.1 TFUE, en la medida en que el IVPEE solo grava la electricidad generada en territorio español, y no aquella que se produce en otros países y que también llega a los consumidores españoles a través de las redes transeuropeas de electricidad. Ello provoca una distorsión de las reglas de mercado, ya que se produce una ventaja competitiva para las empresas que producen electricidad fuera de España respecto de aquellas que desarrollan su actividad de generación en territorio nacional. Por tanto, ello estaría obstaculizando la consecución de un verdadero mercado interior de la electricidad, totalmente interconectado, que incremente la libre competencia y que defina un marco armonizado para el comercio transfronterizo de electricidad, impidiendo así el cumplimiento de los objetivos principales de la Directiva (UE) 2019/944 del Parlamento Europeo y del Consejo, de 5 de junio de 2019, sobre normas comunes para el mercado interior de la electricidad (en adelante, Directiva de MIE) ${ }^{56}$ y del Reglamento (UE) 2019/943 del Parlamento Europeo y del Consejo, de 5 de junio de 2019, relativo al mercado interior de la electricidad (en adelante, Reglamento de MIE) ${ }^{57}$.

En definitiva, solo queda esperar al fallo del TJUE para saber si los generadores que han impugnado sus autoliquidaciones podrán recuperar las cuotas ya satisfechas. En caso de que el TJUE resuelva en sentido favorable a la existencia de incompatibilidad entre el IVPEE y el Derecho de la Unión, ello implicaría la desaparición del IVPEE y, en consecuencia, como ya sucedió con la suspensión del impuesto durante seis meses, la eliminación de la partida incluida en la "retribución específica», dentro de los "costes de operación", destinada devolver parcialmente el impuesto a estos generadores renovables acogidos al régimen retributivo primado.

\section{CONCLUSIONES}


Primera. La Ley 15/2012 atribuye al IVPEE un carácter directo. Sin embargo, entendemos que no cabe apreciar tal carácter en relación con los contribuyentes que utilizan fuentes de energía renovable para generar la electricidad, y en concreto aquellos que están acogidos al «régimen retributivo específico» (régimen de primas). Este tipo de generadores recibirá la devolución parcial del IVPEE a través del concepto "coste de operación" contenido en la «retribución específica", lo nos mostraría cómo son los consumidores finales los que satisfacen, al menos parcialmente, este impuesto estatal. Todo ello habida cuenta de que esta retribución primada que reciben las tecnologías de generación renovable es soportada por el consumidor final en la factura eléctrica, de forma repartida entre el Término Potencia (o término fijo) y el Término Energía (o término variable). Una evidencia clara de que estamos ante un impuesto indirecto fue el propio RDL 15/2018, ya que contempló la suspensión del IVPEE por periodo de seis meses, aduciendo que se trataba de una medida dirigida a proteger a los hogares que no podían soportar los elevados precios de la electricidad en los meses de mayor demanda energética; esto es, una medida dirigida a proteger a los consumidores, en tanto se observan niveles de pobreza energética muy acentuados. En este orden de cosas, cabe subrayar que esta devolución parcial del impuesto no operará para aquellos generadores renovables que no estén acogidos al régimen específico, así como tampoco para las plantas de generación tradicionales (aquellas que obtienen la energía de la combustión de combustibles fósiles, como el carbón y el gas).

Segunda. EI IVPEE busca incrementar la recaudación y con ello hacer frente al cuantioso déficit tarifario acumulado de que adolece el sistema eléctrico español, entendido como un desajuste producido entre los ingresos y los costes reales del sistema; esto es, una situación en la que los precios regulados no van a ser suficientes para satisfacer los costes reales que se asocian a esos precios regulados. Por tanto, el fin perseguido con este impuesto es estrictamente recaudatorio. A nuestro juicio, admitiendo la imperante necesidad de reducir el elevado déficit de tarifa acumulado que hoy en día aún padece el sistema, podrían existir otros instrumentos más adecuados para combatir este desajuste entre ingresos y gastos, como sacar estas cantidades relativas al déficit a Presupuestos Generales del Estado. Con ello se evitarían los agravios que 
produce el IVPEE, ya que habrá unos generadores que soportan más carga tributaria que otros, y que, por tanto, estarían contribuyendo en mayor medida a reducir una deuda -el déficit de tarifa- que es de todos, y que debería ser soportada por todos (generadores y consumidores) en misma proporción.

Tercera. EI IVPEE y el IAE podrían estar recayendo sobre una idéntica manifestación de riqueza de los contribuyentes, ya que sus bases imponibles las integran los importes totales que perciben los contribuyentes por la actividad empresarial de generación de electricidad que desarrollan. Sin embargo, atendiendo a lo dispuesto en el artículo 6 LOFCA, solo cabe apreciar doble imposición cuando concurre un impuesto autonómico con un impuesto local o estatal. Es por ello que la concurrencia entre un impuesto estatal (IVPEE) y un impuesto local (IAE) no plantearía problemas de doble imposición. En este orden de cosas, a los efectos de apreciar una posible doble imposición, no procede entrar a analizar si el IVPEE contiene un fin estrictamente recaudatorio o, por el contrario, presenta un fin extrafiscal, ya que no concurre ningún impuesto autonómico que reclamase hacer tal análisis. Por tanto, descartada esta posibilidad, solo queda analizar si el IVPEE es contrario a los principios de capacidad y de prohibición de la confiscatoriedad (artículo 31.1 CE), a lo que cabe señalar que no existe contrariedad alguna con estos principios, ya que el impuesto manifiesta suficiente capacidad económica y no priva al contribuyente de sus rentas y propiedades, agotando la riqueza imponible.

Cuarta. La Ley 15/2012 trata de atribuir un fin medioambiental al IVPEE. Sin embargo, se observa que la finalidad única de este impuesto es recaudatoria, a los efectos de hacer frente al cuantioso déficit tarifario acumulado que aún padece el sistema eléctrico español. Además, no cabe apreciar finalidad medioambiental alguna en la medida en que no se observa en la estructura del impuesto un trato diferenciado que atienda el nivel de daño ambiental que provoca cada instalación en función del tipo de tecnología que utilizan y de su tamaño. En otras palabras, el gravamen a aplicar va a ser el mismo independientemente de si la instalación de generación es de origen renovable o si se trata de una instalación tradicional (donde la electricidad proviene de la combustión de combustibles fósiles). Solo se contempla una devolución parcial 
del impuesto para generadores renovables acogidos al régimen primado, pero ello no alcanza a todas las tecnologías renovables activas, y no es suficiente para afirmar, de forma inequívoca, que ello constituye un incentivo a producir con energías renovables. Asimismo, no habrá trato diferenciador que atienda el nivel de daño ambiental que provoca cada instalación de generación en función de su tamaño, lo que habría sido exigible en la medida en que a mayor tamaño de la instalación, mayores son las necesidades de refuerzo y ampliación de las redes eléctricas que van a soportar la evacuación de energía, y, por tanto, mayores son los niveles de daño ambiental provocados. Por tanto, no cabe apreciar el pretendido fin medioambiental en ninguno de los elementos que constituye el IVPEE.

Quinta. Admitida la inexistencia de finalidad medioambiental en el IVPEE, cabe plantearse la posible incompatibilidad de este impuesto con el Derecho de la Unión Europea, y en concreto con la Directiva 2020/262. La norma europea establece que solo podrán imponerse otros gravámenes indirectos a los productos ya sujetos a impuestos especiales cuando existan fines específicos que lo justifiquen. Además, esta inexistencia de fin medioambiental supondría dar un paso atrás en la hoja de ruta definida en relación con el fomento de las energías renovables en la Directiva 2008/118/CE. Por tanto, descartada la posibilidad de contemplar tales fines, al solo existir fines de carácter recaudatorio, el IVPEE sería incompatible con estas previsiones normativas europeas. Asimismo, gravar la energía eléctrica generada solo en territorio nacional implica otorgar ventajas competitivas a generadores que se ubican en otros países, y que venden su producto en España, con la consiguiente obstaculización que ello comporta para la proyección efectiva del principio de libre competencia -principio consagrado contenido en el TFUE- y para la consecución de un mercado interior de electricidad -cuyas bases aparecen definidas en la Directiva de MIE y en el Reglamento de MIE-.

Sexta. El TSJ de Valencia ha elevado una cuestión prejudicial al TJUE, al entender, como sostiene la doctrina mayoritaria, que el IVPEE es un impuesto indirecto sin finalidad extrafiscal, y por lo tanto incompatible con el Derecho de la Unión. Así pues, de sustanciarse un fallo del TJUE que confirme la pretendida 
incompatibilidad, los generadores que han impugnado sus autoliquidaciones hasta obtener una sentencia firme (tal y como exige el artículo 32.5 LRJSP), podrán recuperar las cuotas del impuesto satisfechas, para lo que deberán emprender, llegado el momento, la acción de responsabilidad patrimonial por daños causados por una norma contraria al Derecho de la Unión. Además, la sustanciación de este fallo del TJUE tendría como consecuencia inmediata la reducción del «régimen retributivo específico» previsto para las plantas de generación de electricidad basadas en fuentes de energía renovables, y en concreto la parte correspondiente a la devolución del IVPEE computada como "costes de operación".

\section{BIBLIOGRAFÍA}

-Alenza García, José Francisco, "Las energías renovables ante la fugacidad legislativa: la mitificación de los principios de (in) seguridad jurídica y de (des) confianza legítima: [A propósito de la STC 270/2015 sobre el nuevo sistema retributivo de las energías renovables], en Actualidad Jurídica Ambiental, núm. $55,2016$.

-Arana, Silvestre y Valle, Álvaro, "Déficit de tarifa. Retrospectiva y futuro de su regulación", en Cuadernos de Energía, núm. 34, 2012.

-Arenas Pinilla, Eva; Barrella, Roberto; Burzaco Samper, María; José Cabrera Cabrera, Pedro; Centeno Hernáez, Efraim; Escribano Alonso, M.E.; Ibáñez Jiménez, Javier; Linares Llamas, Pedro; Romero Mora, José Carlos y Sanz Bayón, Pablo, "La pobreza energética en España", en Agustín Blanco Martín, Antonio Manuel Chueca Sánchez, José Antonio López Ruiz y Sebastián Mora Rosado (coord.), Informe España 2019, Ed. Universidad Pontificia Comillas. Salamanca, 2019.

-Campos Sánchez-Bordona, Manuel, "Regulación como finalidad distinta al derecho a la competencia”, en Javier Guillén Caramés (dir.), Derecho de la competencia y regulación en la actividad de las Administraciones Públicas, Thomson Civitas. Navarra, 2011, p. 87-103. 
-Casas Agudo, Daniel, "Sobre la legitimidad constitucional de la concurrencia del Impuesto sobre el Valor de la Producción de la Energía Eléctrica y el Impuesto sobre Actividades Económicas. A propósito del Auto del Tribunal Constitucional núm. 69/2018, de 20 de junio", en Nueva fiscalidad, núm. 4, 2018.

-Del Guayo Castiella, İñigo, "Consumidores vulnerables en el sector eléctrico, lucha contra la pobreza energética y el bono social", en Revista de Administración Pública, núm. 203, 2017.

-De la Quadra-Salcedo y Fernández del Castillo, Tomás, "Riesgo regulatorio y contractualización de la regulación por operadores y poderes públicos”, en Juan Castro-Gil Amigo (coord.), Riesgo regulatorio en las energías renovables, Thomson Reuters Aranzadi. Navarra, 2015, p. 29-80.

-Estoa Pérez, Abel y Bacigalupo Saggese, Mariano, “La financiación del déficit del sistema eléctrico: jurisprudencia reciente y regulación en la nueva ley del sector", en Revista de Derecho de la Competencia y la Distribucion, núm. 14, 2014.

-Estoa Pérez, Abel, "La limitación de las ayudas de estado a las energías renovables: las nuevas directrices de la Comisión Europea y el caso español", en Revista Española de Derecho Europeo, num. 53, 2015.

-García Moreno, Alberto, "El Impuesto sobre el Valor de la Producción de Energía Eléctrica (IVPEE) y el Impuesto sobre Actividades Económicas. Una doble imposición constitucional", en Carta tributaria. Revista de opinión, núm. 43, 2018.

-Galera Rodrigo, Susana, "Del ahorro de energía a la eficiencia energética: objetivos e instrumentos de las políticas europeas", en Revista de Derecho Urbanístico y Medio Ambiente, núm. 289, 2014.

-González Ríos, Isabel, "La mejora de la eficiencia energética en edificaciones del litoral (propuesta para una interpretación integrada de la legislación de costas y de la normativa sobre eficiencia energética)", en Revista Española de Derecho Administrativo, núm. 167, 2014. 
-González Ríos, Isabel, "Régimen jurídico de la eficiencia y el ahorro energético”, en Revista Jurídica de Navarra, núm. 50, 2010.

-Lasheras García, Fernando y Arteta Arnaiz, Sergio, "El déficit de tarifa y las reformas para corregirlo. El punto de vista comunitario", en Cuadernos de Energía, núm. 43, 2014.

-Leiva López, Alejandro D., "Cambios de modelo retributivo de la generación renovable en España: la confianza del inversor frente al riesgo regulatorio", en Revista Española de Derecho Administrativo, núm. 188, 2017.

-Leiva López, Alejandro D. "El sector fotovoltaico frente a las reformas regulatorias en materia de ayudas a la producción de electricidad basada en fuentes de energía renovables", en Revista General de Derecho Administrativo, núm. 49, 2018.

-López Sako, Masao Javier, "El reto de las energías renovables en el mercado energético", en Roberto Galán Vioque, Isabel González Ríos y Fernando López Ramón (dirs.), Derecho de las energías renovables y la eficiencia energética en el horizonte 2020, Thomson Reuters Aranzadi. Navarra, 2017, pp. 147-155.

-Marín Uribe, Pedro, "El déficit de tarifa", en Cuadernos de Energía, núm. 25, 2009.

-Mateu de Ros Cerezo, Rafael, "El déficit de la tarifa eléctrica: origen y regulación por el derecho positivo", en Fernando Becker Zuazua, Luis María Cazorla Prieto, Julián Martínez-Simancas Sánchez y José Manuel Sala Arquer (coord.), Tratado de regulación del sector eléctrico, vol. 1 (aspectos jurídicos), Thomson Reuters Aranzadi. Navarra, 2009, p. 347-390.

-Nebreda Pérez, Joaquín María, "El régimen especial de producción eléctrica", en Santiago Muñoz Machado (dir.), Derecho de la regulación económica, Vol. 3, Tomo 1, lustel. Madrid, 2009, p. 381-444.

-Ortiz Calle, Enrique, "Compatibilidad del impuesto sobre el valor de la producción de la energía eléctrica con el derecho de la Unión Europea”, en 
Estudios financieros. Revista de contabilidad y tributación: Comentarios, casos prácticos, núm. 437-438, 2019.

-Ortiz Calle, Enrique, "Los impuestos energéticos de la Ley 15/2012: problemas comunitarios y constitucionales", en Estudios financieros. Revista de contabilidad y tributación: comentarios, casos prácticos, núm. 403, 2016.

-Parejo Alfonso, Luciano José, "Cambio regulatorio, sector eléctrico y estado de necesidad", en Juan Castro Gil-Amigo (coord.), Riesgo regulatorio en las energías renovables, vol. 1, Thomson Reuters-Aranzadi. Navarra, 2015, p. 2972.

-Renieblas Dorado, Pablo, "Impuesto sobre el Valor de la Producción de la Energía Eléctrica: plazo de prescripción del derecho a solicitar la devolución de ingresos indebidos en el Impuesto sobre el Valor de la Producción de Energía Eléctrica. Pagos fraccionados", en Carta Tributaria. Revista de Opinión, núm. 28, 2017.

-Renieblas Dorado, Pablo, "Impuesto sobre el Valor de la Producción de Energía Eléctrica (IVPEE), base imponible y cálculo de pagos fraccionados, aplicación del criterio de devengo o el criterio de caja: Resolución del Tribunal EconómicoAdministrativo Central de 18 de septiembre de 2019", en Carta Tributaria. Revista de Opinión, núm. 61, 2020.

-Revuelta Pérez, Inmaculada, "Estándar del inversor prudente y confianza legítima", en Revista de Administración Pública, núm. 208, 2019.

-Serrano González, Marina, "Nueva regulación de la distribución de energía eléctrica en las Circulares de la Comisión Nacional de los Mercados y la Competencia”, en Cuadernos de Energía, núm. 60, 2019. 